\title{
Heterozygous Fabry women are not just carriers, but have a significant burden of disease and impaired quality of life
}

Raymond $Y$. Wang, $M D^{1,2}$, Alicia Lelis, $M S^{1}$, James Mirocha, $P h D^{3}$, and William R. Wilcox, $M D, P h D^{1,2,4}$

\begin{abstract}
Purpose: To determine if there is significant symptomatology in women with heterozygous $\alpha$-galactosidase mutations. Methods: Data from medical records of the 44 heterozygous females followed at Cedars-Sinai Medical Center were compiled and analyzed for symptoms of Fabry disease. Quality of life data were also analyzed. Results: Seventy-six percent were referred due to an affected male relative; $76 \%$ reported acroparesthesias as their first symptom. A mean of 15.7 years elapsed from onset of first symptoms to the diagnosis. Quality of life, measured by the SF-36 survey, was globally reduced. Pain affected mood and enjoyment of life. Central/peripheral nervous, cardiopulmonary, and renal system manifestations of Fabry disease were present far above that predicted for random X-inactivation of the normal allele. Fatigue, present in $59 \%$, was associated with reduced maximum oxygen consumption ( $P=0.049$ ); exercise intolerance, present in $83 \%$, was associated with reduced maximal heart rate during exercise testing $(P=0.0089)$. Women diagnosed via family history experienced more angina $(P=0.035)$, decreased vibration sense $(P=0.026)$, and had a worse percentage predicted $\mathrm{FEF}_{25-75}(P=0.037)$ compared to women diagnosed because of symptoms. Conclusions: This study indicates that the asymptomatic female carrier of Fabry disease is the exception, not the rule: heterozygotes suffer from significant multisystemic disease and reduced quality of life and must be monitored and treated accordingly. Genet Med 2007:9(1):34-45.
\end{abstract}

Key Words: Fabry disease, female, heterozygote, natural history, outcome, SF-36, symptom, quality of life

Fabry disease (MIM \#301500) is an X-linked lysosomal storage disorder caused by deficiency of the enzyme $\alpha$-galactosidase A [ $\alpha$-gal A, E.C. 3.2.1.22]. ${ }^{1}$ Affected patients have an impaired ability to degrade membrane glycosphingolipids containing a terminal $\alpha$-glycosidic galactose, especially globotriaosylceramide/ceramide trihexoside $\left(\mathrm{GL}_{3}\right)$, which accumulates in tissues. Storage in the vascular endothelium increases the risk for cerebrovascular accidents (CVA) and myocardial microvascular ischemia ${ }^{2-4}$; in the heart causes dysrhythmias, hypertrophic cardiomyopathy, and valvular insufficiency ${ }^{5}$; in the kidney leads to progressive renal insufficiency and eventually failure ${ }^{6}$; in the peripheral nervous system gives rise to gastrointestinal dysmotility, hypohidrosis, temperature intolerance, dysregulation of vascular tone, and characteristic acroparesthesias of the hands and feet. ${ }^{7-9}$ Obstructive lung disease and impaired exercise tolerance are also seen. ${ }^{10-12}$

\footnotetext{
From the ${ }^{1}$ Medical Genetics Institute, Cedars-Sinai Medical Center, Los Angeles, California; ${ }^{2}$ Department of Pediatrics, Cedars-Sinai Medical Center, Los Angeles, California; ${ }^{3}$ Biostatistics Core, Research Institute, Cedars-Sinai Medical Center, Los Angeles, California; ${ }^{4}$ Department of Pediatrics, UCLA School of Medicine, Los Angeles, California.

William R. Wilcox, MD, PhD, Medical Genetics Institute, Cedars-Sinai Medical Center, 8700 Beverly Blvd, SSB-378, Los Angeles, CA 90048.E-mail:william.wilcox@cshs.org

Submitted for publication July 14, 2006.

Accepted for publication October 31, 2006.

DOI: 10.1097/GIM.0b013e31802d8321
}

Fabry disease causes significant morbidity and mortality in hemizygous males. Acroparesthesias and gastrointestinal upset reduce emotional well-being and productivity. Patients become deconditioned due to exercise intolerance. Proteinuria and renal insufficiency begin in the third to fourth decades of life in males. ${ }^{6}$ Death occurs typically in the fifth decade; renal failure is the most common cause of death in patients with Fabry disease, followed closely by stroke and myocardial infarction. ${ }^{13}$

As recently as 2001, women with heterozygous mutations in the $\alpha$-gal A gene were thought to be asymptomatic carriers of the disease due the presence of functional $\alpha$-gal A enzyme synthesized from the normal allele. ${ }^{14}$ Symptoms in heterozygotes were attributed to skewed X-inactivation of the normal allele. Recently, several groups have reported that carrier women develop symptoms of Fabry disease at a higher rate than can be predicted simply by skewed X-inactivation and are at a higher risk of premature death. ${ }^{15-19}$ Although genotype-phenotype and $\alpha$-gal A activityphenotype correlations are fairly well described in hemizygous men, ${ }^{20-24}$ the few studies that have been performed in heterozygotes fail to show similar correlations. ${ }^{18,19}$ Due to the low prevalence of Fabry disease, most cohort studies are small, limiting the amount of data regarding the frequency and severity of Fabry disease manifestations in heterozygous women. The Fabry Outcomes Survey (FOS), a European registry of Fabry patients, reported symptoms and manifestations in more than 300 women and is the largest published natural history survey of heterozygotes 
to date. ${ }^{18}$ The Fabry Registry (http://www.fabryregistry.com) is currently analyzing data from 809 female Fabry patients.25-27 While extremely informative, registry-based studies are subject to limitations. Measured parameters and outcomes record a limited amount of clinical data, are not monitored systematically during submission, and are subject to ascertainment bias because registries tend to enroll the sicker, more symptomatic patients who require treatment with enzyme replacement therapy (ERT).

Multiple studies have demonstrated biweekly intravenous infusions with recombinant human $\alpha$-gal A effectively improve anhidrosis, pulmonary gas exchange, gastrointestinal symptoms, and acroparesthesias; stabilize renal function; and reduce plasma and tissue $\mathrm{GL}_{3}$ accumulation. ${ }^{28-34}$ However, the trials were performed almost exclusively on males, with only two females involved in the United States Phase IIIa and eight in the phase IIIb trial. One open-label study involving 15 heterozygous females demonstrated reduction in plasma and tissue $\mathrm{GL}_{3}$, preserved creatinine clearance, improved quality of life, and reduced left ventricular mass after 41 weeks of ERT. ${ }^{35}$

Thirty-four heterozygous women are followed at Cedars-Sinai Medical Center (CSMC) and are seen every 6-12 months. 11 are currently receiving ERT. An additional ten women were seen at CSMC as part of a survey study. Most of the women were ascertained through affected male family members and thus are more representative of Fabry carriers in general. Many women were noted to complain of fatigue, exercise intolerance, and acroparesthesias. Regardless of ascertainment method, the majority of heterozygous females have clinically significant Fabry disease symptoms and clinical manifestations.

\section{MATERIALS AND METHODS}

\section{Patient recruitment and evaluation}

CSMC is the largest referral center for Fabry disease in the Southwestern United States. The Fabry Registry study was approved by the CSMC institutional review board. All women seen at CSMC for Fabry disease are recruited for the study and sign the informed consent form prior to entry into the Registry. All women have a detailed history and physical performed upon entry into the study and at periodic intervals by WRW. The diagnosis of Fabry disease was made by a combination of pedigree analysis, $\alpha$-Gal A plasma and leukocyte enzyme activity, and molecular genotyping.

\section{Data analysis and statistics}

Data gathered from our patients regarding the presence, onset, and severity of cerebral, cardiovascular, renal, gastrointestinal, and neuropathic disease was compiled. Pain was measured with the Basic Pain Inventory (BPI) survey, which contains questions relating to pain and degree of interference with daily living, and is the standard instrument of pain assessment for Fabry disease. ${ }^{7,36-39}$ Answers range from 0 (no pain or interference with activity) to 10 (most severe pain and interference with activity). Quality of life was measured both by patient interview, focusing on subjective estimation of fatigue, exercise tolerance, depression/current antidepressive medica- tion use, and anxiety, and by the SF-36 health-related quality of life survey. The SF-36 survey is a 36 -item questionnaire that measures a patient's subjective estimation of quality of life and is divided into two composite scores: the physical and mental component summary scores (PCS and MCS), and eight subcomponent scores: physical functioning, role physical, bodily pain, general health, vitality, social functioning, role emotional, and mental health (http://www.sf36.org). It is a validated, reliable measure of quality of life and has been used for patients with Fabry disease as well as other chronic diseases such as asthma, renal failure, and autoimmune disease. ${ }^{39-42}$ Scores were compared to United States female population norms. ${ }^{43}$ Differences were reported as standardized response means, also known as effect sizes, equivalent to the difference in means divided by the standard deviation of the norm group. An effect size of 0.8 is defined to be large and indicates the mean of the study group is at the $21^{\text {st }}$ percentile of the control group. ${ }^{44}$

Cerebrovascular disease (CVD) was assessed by reviewing medical records and brain imaging for transient ischemic attacks (TIAs) and CVAs. Magnetic resonance brain imaging was obtained without contrast, utilizing axial $\mathrm{T}_{1}, \mathrm{~T}_{2}$, and FLAIR techniques. Patients were also asked to report if they experienced tinnitus and subjective loss of hearing. When available, audiology reports were reviewed for objective evidence of hearing loss. Small-fiber, autonomic, and dorsal column neuropathy were evaluated by subjective reports of acroparesthesias, hypohidrosis, and heat/cold intolerance, and objective examination for decreased vibration sense.

A standard 12-lead electrocardiogram (EKG) and transthoracic echocardiogram were obtained. Resting heart rate and blood pressure were obtained during clinical evaluations. Heart rate, PR interval, and dysrhythmias (as assessed by EKG) and left ventricular posterior wall distance $\left(\mathrm{LVPW}_{\mathrm{d}}\right) /$ intraventricular septal distance $\left(\mathrm{IVS}_{\mathrm{d}}\right)$, valvular function, and ejection fraction (as assessed by echocardiogram) were obtained.

Pulmonary function testing was performed and evaluated in accordance with American Thoracic Society Standards. The protocol, methods of analysis, and results of the women studied for noninvasive exercise testing have been described previously, as have the results for some of the women studied herein. ${ }^{12}$ Results of pulmonary function testing (percent predicted $\mathrm{FEV}_{1}, \mathrm{FVC}, \mathrm{FEV}_{1} / \mathrm{FVC}$ ratio, $\mathrm{FEF}_{25-75}$ ), as well as exercise tolerance testing (percent predicted $\mathrm{VO}_{2 \text { max }}$, heart rate as a percentage of maximum predicted heart rate, and systolic and diastolic blood pressures) were compiled and correlated to subjective complaints of exercise intolerance and fatigue.

Renal function was assessed for the presence of proteinuria (defined as $>150 \mathrm{mg}$ protein/24 hours), microalbuminuria (defined as $>30 \mathrm{mg}$ albumin/24 hours), serum creatinine, and measured (if not available, calculated using the Modified Diet in Renal Disease equation) creatinine clearance. ${ }^{45}$ If spot urine protein, creatinine, and/or microalbumin were obtained instead of 24-hour timed urine collection, proteinuria was defined as a urine protein:creatinine ratio of $>0.015$ or a urine microalbumin concentration exceeding $30 \mathrm{mg} / \mathrm{L}$. Gastrointestinal involvement centered on subjective complaints of ab- 
dominal pain and bowel dysmotility. Charts were also reviewed for concurrent medications and the presence of comorbid cardiovascular risk factors such as hypertension, diabetes mellitus, and dyslipidemias. Categorical variables were reported as percentages. Continuous variables were reported as mean (median) \pm standard deviation (SD).

Data from women who were ascertained due to a diagnosis of Fabry disease in an affected family member were compared with data from women ascertained based on symptoms. Similarly, the results of pulmonary function and noninvasive exercise testing were compared in women with and without fatigue, and women with and without exercise intolerance. Representative symptoms from major organ systems affected by Fabry disease were selected: the mean age, plasma $\alpha$-gal A, and leukocyte $\alpha$-gal A activity of women affected and not affected by the symptom were calculated and compared. The representative symptoms were CVD, acroparesthesias, hypohidrosis, angina pectoris, left ventricular hypertrophy, valvular dysfunction, GI cramping and/or diarrhea, and end-stage renal disease. $\mathrm{FEF}_{25-75}, \mathrm{VO}_{2 \max }$, maximum heart rate attained during exercise, creatinine clearance, and 24-hour urine protein excretion were analyzed according to patient age, plasma $\alpha$-gal A, and leukocyte $\alpha$-gal A activity.

Categorical variables were compared using Fisher's exact test. Continuous variables that satisfied both normality and homogeneity of variance assumptions were compared using Student's $t$-test. Satterthwaite's approximate $t$-test was employed for variables that satisfied only the normality assumption, while the Wilcoxon Rank-Sum test was used for variables that did not satisfy the normality assumption. Correlations between numeric variables were assessed by Spearman (rankorder) correlation analysis. In all comparisons, two-tailed $P$ values were calculated and reported.

\section{RESULTS}

\section{Demographic data and initial symptomatology}

Data on 44 Fabry heterozygotes were available for review (Table 1). The patient age was 46.1 (48) \pm 17.4 years. Seventysix percent (31/41) were ascertained following diagnosis of another affected family member, $15 \%$ (6/41) due to renal disease, $4.9 \%(2 / 41)$ due to cornea verticillata, and $4.9 \%(2 / 41)$ due to acroparesthesias. Overall, acroparesthesias were the first reported symptom in $76 \%(16 / 21)$ of women. The age of the first reported symptom was $13.8(10) \pm 10.7$ years, but the age of diagnosis was $29.5(27) \pm 19.9$ years. By recall, most of the women developed their first symptom during the first two decades of life: $42 \%(14 / 33)$ at age $0-9$ years, $42 \%(14 / 33)$ at age $10-19$ years, $6 \%(2 / 33)$ at age $20-29$ years, $3 \%(1 / 33)$ at age $30-39$ years, and $6 \%(2 / 33)$ at age exceeding 39 years. The different $\alpha$-gal A mutations of the cohort are summarized in Table 2. The leukocyte $\alpha$-gal A activity was $14.6(8.5) \pm 19.3$ $\mathrm{nmol} / \mathrm{mg}$ protein/hour, while the plasma $\alpha$-A activity was 4.8 (2.6) $\pm 8.4 \mathrm{nmol} / \mathrm{mg}$ protein/hour.

The body mass index of the cohort (BMI) was 28.8 (28.8) \pm $7.89 ; 68 \%(28 / 41)$ had a body mass index (BMI) above the
Table 1

General demographic data for the CSMC Fabry heterozygote cohort

\begin{tabular}{|c|c|c|c|c|}
\hline & Mean & SD & Median & $\Lambda$ \\
\hline Age (years) & 46.1 & 17.4 & 48 & 42 \\
\hline Age of first symptom (years) & 13.8 & 10.7 & 10 & \\
\hline Age of diagnosis (years) & 29.5 & 19.9 & 27 & \\
\hline Weight (kg) & 74.7 & 20.3 & 73.2 & \\
\hline Height (cm) & 160.9 & 6.3 & 160 & \\
\hline Body Mass Index $\left(\mathrm{kg} / \mathrm{m}^{2}\right)$ & 28.8 & 7.9 & 28.8 & \\
\hline Body Surface Area $\left(\mathrm{m}^{2}\right)$ & 1.8 & 0.3 & 1.8 & \\
\hline $\begin{array}{l}\text { Plasma } \alpha \text {-Gal A activity }{ }^{a} \\
\quad(\mathrm{nmol} / \mathrm{hr} / \mathrm{mL})\end{array}$ & 4.8 & 8.4 & 2.6 & \\
\hline $\begin{array}{l}\text { Leukocyte } \alpha \text {-Gal A activity } \\
\quad(\mathrm{nmol} / \mathrm{hr} / \mathrm{mL})\end{array}$ & 14.6 & 19.3 & 8.5 & \\
\hline
\end{tabular}

${ }^{a}$ Normal range $12 \pm 4.2 \mathrm{nmol} / \mathrm{hr} / \mathrm{mL} ;{ }^{b}$ Normal range $34.6 \pm 14.6 \mathrm{nmol} /$ $\mathrm{hr} / \mathrm{mL}$.

Table 2

Specific mutations and prevalence in the CDMC Fabry heterozygote cohort

\begin{tabular}{|c|c|c|}
\hline Mutation & Number & Prevalence \\
\hline \multicolumn{3}{|c|}{ Missense $(\mathrm{N}=23)$} \\
\hline A31V & 1 & $4.3 \%$ \\
\hline G43R & 1 & $4.3 \%$ \\
\hline $\mathrm{R} 112 \mathrm{C}$ & 2 & $8.6 \%$ \\
\hline G138E & 1 & $4.3 \%$ \\
\hline Y207S & 2 & $8.6 \%$ \\
\hline $\mathrm{A} 230 \mathrm{~T}$ & 1 & $4.3 \%$ \\
\hline G261D & 1 & $4.3 \%$ \\
\hline $\mathrm{N} 272 \mathrm{~K}$ & 9 & $39 \%$ \\
\hline M290I & 1 & $4.3 \%$ \\
\hline G328V & 1 & $4.3 \%$ \\
\hline $\mathrm{R} 363 \mathrm{H}$ & 3 & $13 \%$ \\
\hline \multicolumn{3}{|c|}{ Nonsense $(\mathrm{N}=18)$} \\
\hline 18del1 & 1 & $5.5 \%$ \\
\hline 26del1 & 1 & $5.5 \%$ \\
\hline $639+4 \mathrm{~A}-\mathrm{T}$ & 1 & $5.5 \%$ \\
\hline 1020del1 & 2 & $11 \%$ \\
\hline 1033 del 2 & 1 & $5.5 \%$ \\
\hline 1072 del 2 & 1 & $5.5 \%$ \\
\hline 1096ins5 & 1 & $5.5 \%$ \\
\hline 11052del2 & 2 & $11 \%$ \\
\hline L177X & 2 & $11 \%$ \\
\hline W162X & 2 & $11 \%$ \\
\hline W226X & 3 & $16 \%$ \\
\hline E338X & 1 & $5.5 \%$ \\
\hline
\end{tabular}


Fabry heterozygotes have significant symptomatology

Table 3

Health-related quality of life in the CSMC Fabry heterozygote cohort compared to U.S. female population norms, as measured by the SF-36 survey

\begin{tabular}{|c|c|c|c|c|c|c|}
\hline & Cohort Mean $(\mathrm{N}=19)$ & US Female Mean $(\mathrm{N}=1412)^{a}$ & Cohort SD & US female SD & Difference & Effect size \\
\hline Physical functioning & 62.2 & 87.2 & 29.7 & 24.6 & 25 & $1.0^{b}$ \\
\hline Bodily pain & 59.2 & 77.8 & 45 & 36.2 & 18.6 & 0.51 \\
\hline Role physical & 64.3 & 73.6 & 26.1 & 24.3 & 9.3 & 0.38 \\
\hline General health & 54.1 & 70.6 & 26.2 & 21.5 & 16.5 & $0.77^{b}$ \\
\hline Vitality & 42.6 & 58.4 & 24.2 & 21.5 & 15.8 & $0.73^{b}$ \\
\hline Social functioning & 69.3 & 81.5 & 26.1 & 23.7 & 12.2 & 0.51 \\
\hline Role emotional & 59.2 & 79.5 & 43.7 & 34.4 & 20.3 & 0.59 \\
\hline Mental health & 65.5 & 73.3 & 22.1 & 18.6 & 7.8 & 0.42 \\
\hline Physical composite summary & 45.4 & 50 & 10.8 & 10 & 4.6 & 0.46 \\
\hline Mental composite summary & 43.3 & 50 & 13.9 & 10 & 6.7 & 0.67 \\
\hline
\end{tabular}

${ }^{a}$ Ware, et al. 1998.

${ }^{b}$ Large effect size.

normal range $(\mathrm{BMI} \geq 25)$ and $44 \%(18 / 41)$ were obese (BMI $\geq$ 30) according to Center for Disease Control definitions. Only one patient, age 24 years, who reported treatment with antidepressants, had no symptoms of Fabry disease.

Of the six women who were diagnosed with Fabry disease due to renal involvement, two sisters (reported previously) were ascertained after one developed end-stage renal disease (ESRD), received a living-related donor kidney from her sister, and underwent a graft renal biopsy following transplant that showed vacuolated renal epithelial cells suggestive of storage. ${ }^{46}$ Molecular analysis confirmed a Y207S $\alpha$-gal A mutation in both.

\section{Quality of life and pain}

The SF-36 mean PCS and MCS scores of the cohort, as well as the eight subcategory scores, were all below the United States female population norms. Norms for the PCS and MCS are 49.6 and 49.1, respectively, with a standard deviation of 10.3 and 10.6, respectively. ${ }^{43}$ The PCS of the cohort was 45.4 (46.5) \pm 10.8 and the MCS was 43.3 (44.5) \pm 13.9 . The effect size was the greatest for the subcategory of physical functioning (1.0), corresponding to a cohort mean at the $16^{\text {th }}$ percentile of the population. The effect size in the general health subcategory was 0.77 (cohort mean $22^{\text {nd }}$ percentile of population) and 0.73 for the vitality subcategory (cohort mean $24^{\text {th }}$ percentile of population). These results are summarized in Table 3 and Figure 1.

The BPI scores of the cohort are summarized in Figure 2. The BPI score for "pain at its worst" was 3.7 (3) \pm 3.5 , for "pain at its least" was $2.1(1) \pm 2.5$, and for "pain on the average" was 2.9 (2) \pm 2.8 . Patients indicated that the pain interfered the most with their mood $[2.9(1.5) \pm 3.2]$, ability to work [2.7 (0.5) \pm 3.5$]$, enjoyment of life [2.6 (1) \pm 3.4$]$, and general activity $[2.6(1.5) \pm 3.3]$.

\section{Neurologic and psychiatric data}

Twenty-four percent (9/37) reported symptoms of TIA and $22 \%(8 / 36)$ had sustained at least one CVA (Table 4). Seven patients had both TIA and CVA. The age of first CVA was 52 (46) \pm 13 years. Periventricular white matter changes on MR brain imaging were visualized in $32 \%(8 / 25)$; three of those eight women had sustained a stroke. The other five women who had white matter changes reported neither TIA nor CVA. Tinnitus was reported in 58\% (22/38) of patients, and subjective/objective evidence of hearing loss (typically high-frequency sensorineural hearing loss) was found in 37\% (14/38). Sixty-five percent (26/40) reported acroparesthesias, with a 23.3 (24) \pm 13.9 -year duration. Forty-nine percent (19/39) reported temperature intolerance, and 60\% (25/42) reported hypohidrosis/anhidrosis. Seventy-nine percent (33/42) were found to have decreased vibration sense in the lower extremities. A large proportion, $62 \%$ (21/34), reported either symptoms of depression or treatment with antidepressants, while $39 \%(13 / 33)$ reported generalized anxiety.

\section{Cardiac data}

Twenty-five percent (9/36) complained of angina (Table 5). Patients who took nitrates reported improvement in chest pain. In the three patients where EKGs and cardiac enzymes (CK-MB and troponin) were obtained during episodes of chest pain, ST segment depression was observed, but elevations in enzymes were found in none. Percutaneous coronary angiography was performed in those patients: plaque formation and stenosis were not observed. Twenty-one percent (8/38) reported palpitations. When Holter or 30-day event monitoring was performed, the most common dysrhythmia was sinus tachycardia. No patient had ventricular tachycardia or paroxysmal atrial fibrillation.

Thirty-six percent (14/39) were found to have resting heart rates $<60$ beats per minute (BPM) on examination, and the heart rate was $67.5(66) \pm 11.5 \mathrm{BPM}$. Thirty-three percent $(11 / 33)$ had sinus bradycardia on EKG. The most common EKG abnormalities were ST-T wave flattening or inversion $(45.5 \%, 15 / 33), \mathrm{LVH}$ by voltage criterion $(21 \%, 7 / 33)$, and $\mathrm{rSR}$ with either normal or prolonged QRS interval $(18 \%, 6 / 33)$. 


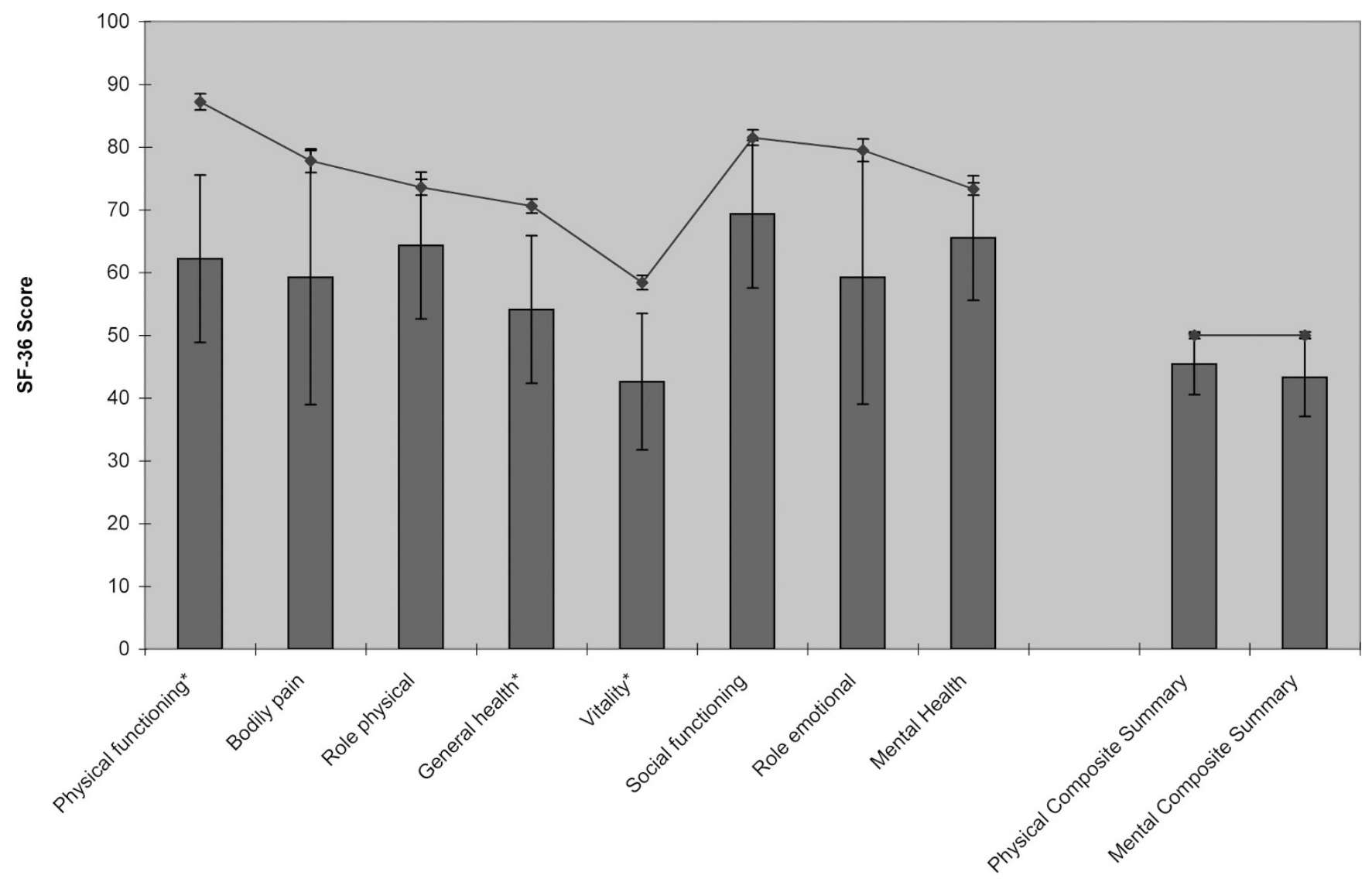

Cohort Mean $\prec$ US Female Norms

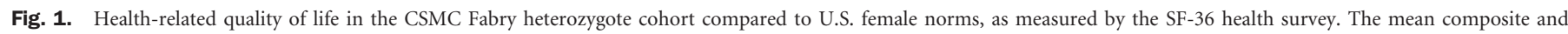

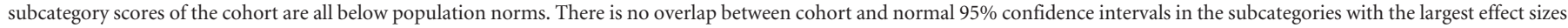
( ${ }^{\star}$ physical functioning, general health, and vitality).

The PR interval was 154.6 (152) \pm 23 milliseconds. One 51year-old patient had a PR interval $<120$ milliseconds ( 114 milliseconds), and two patients (aged 57 and 76 years) had PR intervals exceeding 200 milliseconds. One patient, age 75, had $\mathrm{a} \mathrm{QT}_{\mathrm{c}}$ interval exceeding 450 milliseconds (503 milliseconds). Her EKG also showed sinus bradycardia, right bundle-branch block, LVH, and type A Wolff-Parkinson-White syndrome that necessitated placement of a pacemaker. Her endomyocardial biopsy demonstrated cardiac myocytes with marked vacuolization, which on electron microscopy were whorled, lamellated structures consistent with storage of $\mathrm{GL}_{3}$.

Six percent (2/33) had echocardiographic evidence of ventricular hypertrophy $\left(\mathrm{LVPW}_{\mathrm{d}}\right.$ and $\left.\mathrm{IVS}_{\mathrm{d}}>12 \mathrm{~mm}\right)$. Ejection fraction (EF) was preserved at $58.3(58) \pm 7.6 \%$. Only one patient had a low EF of $35 \%$. Although her $\mathrm{LVPW}_{\mathrm{d}}$ and $\mathrm{IVS}_{\mathrm{d}}$ were normal (10 and $11 \mathrm{~mm}$, respectively), her EKG showed left atrial enlargement, left bundle-branch block, and positive voltage criterion for LVH. Mitral (MR) or aortic regurgitation (AR) was found in $58 \%(18 / 31)$. Of these 18 women, none had moderate or worse valvular dysfunction; none required valve replacement surgery. None of the women suffered from heart failure as a result of valve dysfunction. Three of the 18 women had left ventricular hypertrophy. Mitral regurgitation was present in all 18: 8 (44\%) had trace MR, 1 (5.6\%) had trace- mild MR, 6 (33\%) had mild MR, and 3 (17\%) had mild-moderate MR. Aortic regurgitation was present in $4(22 \%)$ : 2 had trace AR and 2 and mild AR.

\section{Pulmonary data}

A significant proportion of women complained of fatigue $(58.5 \%, 24 / 41)$ and exercise intolerance $(82.5 \%, 33 / 40)$. The $\mathrm{FEV}_{1}$ was $94(92) \pm 18.3 \%$ predicted, FVC was $104.1(104) \pm$ $15.2 \%$ predicted, $\mathrm{FEV}_{1}$-to-FVC ratio was $77.5(79) \pm 12.6 \%$, and $\mathrm{FEF}_{25-75}$ was $71.8(76) \pm 27.7 \%$. Evidence of obstructive lung disease was observed: $15 \%(4 / 26)$ had an abnormal $\mathrm{FEV}_{1^{-}}$ to-FVC ratio, and $47 \%(8 / 17)$ had a $\mathrm{FEF}_{25-75}<70 \%$ of predicted. One nonsmoking 48-year-old patient with a prior stroke who complained of fatigue, persistent cough, and shortness of breath was found to have pulmonary infiltrates on chest radiography and "ground-glass" opacities on chest CT. She subsequently underwent a right upper lobe lung biopsy that showed peribronchiolar fibrosis and inclusion bodies within the smooth muscle and endothelial cells of the bronchioles and arterioles. Electron microscopy indicated the inclusion bodies were lamellated zebra bodies consistent with $\mathrm{GL}_{3}$ storage.

Noninvasive exercise testing demonstrated abnormalities in gas exchange and cardiopulmonary response, with the $\mathrm{VO}_{2 \max }$ $78.5(79.5) \pm 25.4 \%$ of predicted and $69 \%(18 / 26)$ with a drop 


\begin{tabular}{lcccc} 
BPI Dimension & $\mathbf{n}$ & Mean & Median & SD \\
\hline Pain at its worst & 19 & 3.7 & 3 & 3.5 \\
Pain at its least & 19 & 2.1 & 1 & 2.5 \\
Pain on the average & 19 & 2.9 & 2 & 2.8 \\
Pain now & 19 & 2.1 & 1 & 2.7 \\
& & & & \\
Interference of pain with: & & & & \\
General activity & 18 & 2.6 & 1.5 & 3.3 \\
Mood & 18 & 2.9 & 1.5 & 3.2 \\
Walking ability & 18 & 1.9 & 0 & 2.9 \\
Normal work & 18 & 2.7 & 0.5 & 3.5 \\
Social relations & 17 & 1.6 & 0 & 2.9 \\
Sleep & 17 & 2.3 & 1 & 3.2 \\
Enjoyment of life & 17 & 2.6 & 1 & 3.4
\end{tabular}

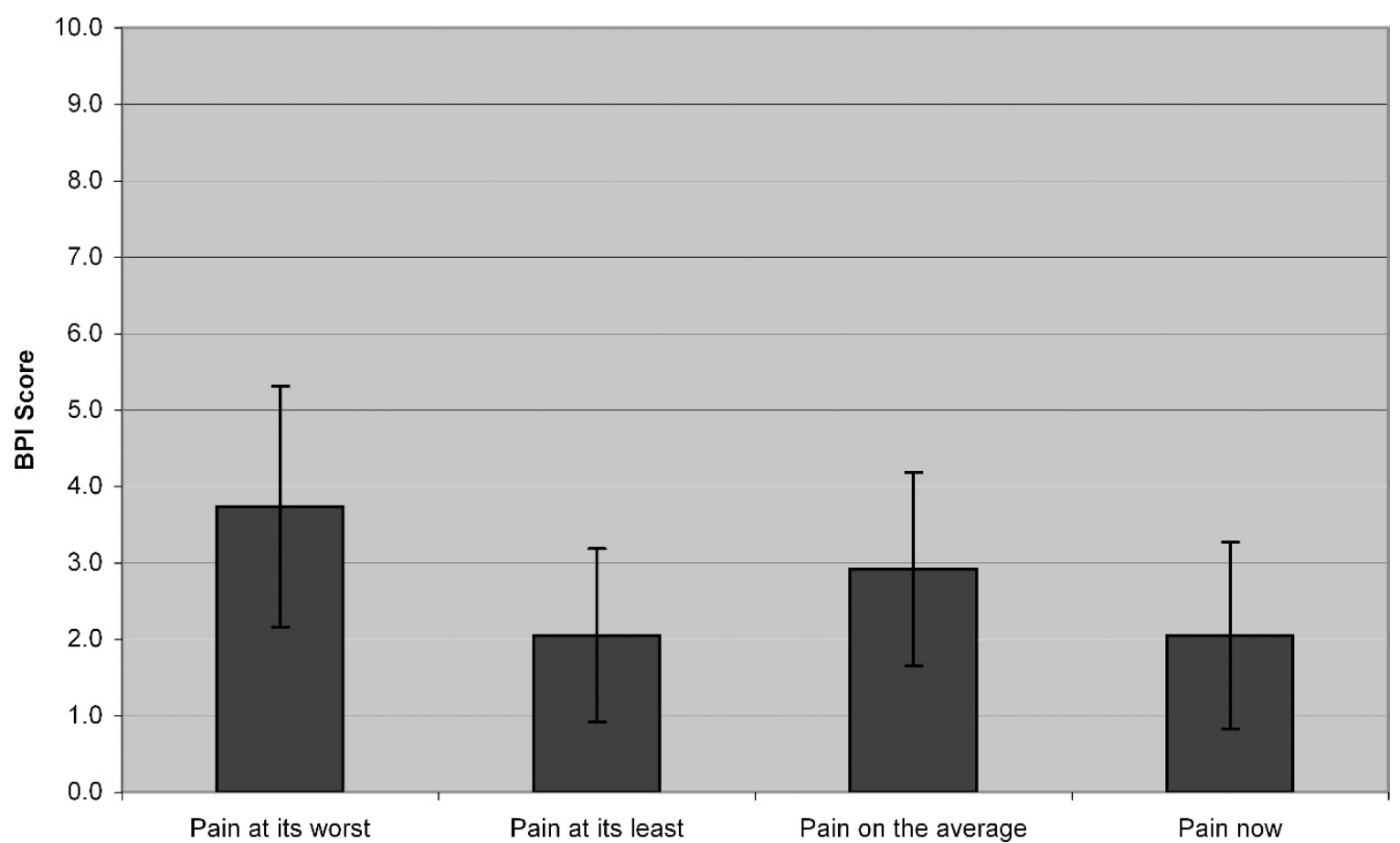

Fig. 2. Chart of BPI dimension scores and degree of interference with various activities of daily living. The BPI dimension scores are plotted in the graph below.

in diastolic blood pressure greater than or equal to $10 \mathrm{mmHg}$. The decrease in DBP was $25.3(19) \pm 13.7 \mathrm{mmHg}$. The spirometry and noninvasive exercise test results are summarized in Table 6. Correlating exercise testing results to subjective symp-

Table 4

Neurologic and psychiatric data for the CSMC Fabry heterozygote cohort

\begin{tabular}{lccc}
\hline & No. positive & N & Prevalence \\
\hline TIA & 9 & 37 & $24 \%$ \\
Stroke & 8 & 36 & $22 \%$ \\
Brain MRI c/w stroke/white matter $\Delta s$ & 8 & 25 & $32 \%$ \\
Tinnitus & 22 & 38 & $58 \%$ \\
Hearing loss & 14 & 38 & $37 \%$ \\
Hypohidrosis & 25 & 42 & $60 \%$ \\
Temperature intolerance & 19 & 39 & $49 \%$ \\
Decreased vibration sense & 33 & 42 & $79 \%$ \\
Acroparesthesia & 26 & 40 & $65 \%$ \\
Depression/antidepressant use & 21 & 34 & $62 \%$ \\
Anxiety/anxiolytic use & 13 & 33 & $39 \%$ \\
\hline
\end{tabular}

toms, the $\mathrm{VO}_{2 \max }$ in women complaining of fatigue was 70.1 (69) $\pm 18.3 \%$ of predicted, compared to $90.3(90) \pm 27.6 \%$ of predicted in the 11 women without fatigue $(P=0.049$, Student's $t$-test'). The maximum heart rate attained during exercise testing was significantly lower in those who complained of exercise intolerance $(85.3(86) \pm 13)$ versus those who did not (113 (98.5) \pm 31.9$),(P=0.0089$, Wilcoxon Rank-Sum test). Otherwise, we observed no other statistically significant differences in pulmonary function tests and other exercise testing parameters between those with and without fatigue, and those with and without exercise intolerance. The results of these comparisons can be found in Table 7.

\section{Renal data}

Five women (12.5\%) had end-stage renal disease (ESRD) and two had received renal transplants (Table 8 ). The three girls younger than 18 years were excluded from creatinine clearance $(\mathrm{CrCl})$ analysis due to lack of measured $\mathrm{CrCl}$ and inaccuracy in the young of formulas used to estimate $\mathrm{CrCl}$. $\mathrm{CrCl}$ was $80(83.3) \pm 33.3 \mathrm{~mL} /$ minute $/ 1.73 \mathrm{~m}^{2}$. If the women with ESRD were excluded, $\mathrm{CrCl}$ was $90.4(86.8) \pm 21.7 \mathrm{~mL} /$ minute $/ 1.73 \mathrm{~m}^{2}$. More than half, $58 \%(21 / 36)$, had a $\mathrm{CrCl}<90$ $\mathrm{mL} /$ minute/1.73 $\mathrm{m}^{2}$, and $19 \%(7 / 36)$ had a $\mathrm{CrCl}<60 \mathrm{~mL} /$ 
Table 5

Cardiac data for the CSMC Fabry heterozygote cohort

\begin{tabular}{|c|c|c|c|c|}
\hline & No. positive & $\mathrm{N}$ & Prevalence & \\
\hline Angina & 10 & 36 & $28 \%$ & \\
\hline Hypertension & 16 & 37 & $43 \%$ & \\
\hline Palpitations & 8 & 38 & $21 \%$ & \\
\hline EKG abnormalities & 25 & 33 & $76 \%$ & \\
\hline Mitral/aortic insufficiency & 18 & 31 & $58 \%$ & \\
\hline \multirow{2}{*}{$\begin{array}{l}\text { LVH (by EKG and/or } \\
\text { Echocardiogram) }\end{array}$} & 8 & 34 & $24 \%$ & \\
\hline & Mean & SD & Median & $\mathrm{N}$ \\
\hline Heart rate (BPM) & 67 & 12 & 66 & 39 \\
\hline PR interval (ms) & 155 & 23 & 152 & 32 \\
\hline $\mathrm{IVS}_{\mathrm{d}}(\mathrm{mm})$ & 9.9 & 1.4 & 10 & 28 \\
\hline $\mathrm{LVPW}_{\mathrm{d}}(\mathrm{mm})$ & 10.1 & 1.7 & 11 & 28 \\
\hline $\mathrm{EF} \%$ & 58 & 7.6 & 58 & 27 \\
\hline
\end{tabular}

Table 6

Spirometry and exercise test data for the CSMC Fabry heterozygote cohort

\begin{tabular}{lcccc}
\hline & No. positive & $\mathrm{N}$ & Prevalence & \\
\hline Fatigue & 24 & 51 & $59 \%$ & \\
Exercise intolerance & 33 & 40 & $83 \%$ & \\
Reduced DBP in exercise & 18 & 26 & $69 \%$ & \\
Spirometry & Mean & $\mathrm{SD}$ & Median & $\mathrm{N}$ \\
$\quad$ Percent predicted (\%) $\mathrm{FEV}_{1}$ & 94.0 & 18.3 & 92 & 27 \\
Percent predicted (\%) FVC & 104 & 15.2 & 104 & 27 \\
FEV -to-FVC ratio & 77.5 & 12.6 & 79 & 27 \\
Percent predicted (\%) $\mathrm{FEF}_{25-75}$ & 71.8 & 27.7 & 76 & 17 \\
Exercise testing & $\mathrm{Mean}$ & $\mathrm{SD}$ & $\mathrm{Median}$ & $\mathrm{N}$ \\
$\quad$ Percent predicted (\%) $\mathrm{HR}$ & 88.7 & 19.5 & 88 & 26 \\
Percent predicted (\%) $\mathrm{VO}_{2 \max }$ & 78.5 & 25.4 & 79.5 & 26 \\
Reduction in DBP $(\mathrm{mm} \mathrm{Hg})$ & 25.3 & 13.7 & 19 & 18 \\
Percent predicted (\%) $\mathrm{V}_{\mathrm{d}} / \mathrm{V}_{\mathrm{t}}$ & 149 & 37.1 & 144 & 25 \\
\hline
\end{tabular}

minute/ $1.73 \mathrm{~m}^{2}$. Proteinuria was present in 56\% (10/18) and microalbuminuria in $80 \%(8 / 10)$. Five women had low-level $(<300 \mathrm{mg} / 24$ hours $)$ and 3 had nephrotic range $(>2000 \mathrm{mg}$ protein/24 hours) proteinuria.

\section{Gastrointestinal data}

Severe abdominal cramping was reported in 39\% (16/41) and diarrhea was reported in $43 \%(18 / 42)$.

\section{Comorbidities, concurrent medications, and enzyme replacement therapy}

Most of the concurrent medications were used for cardiovascular risk reduction or pain control. Hypertension or treatment with antihypertensives was present in 43\% (16/37) of all
Table 7

Comparison and statistical analysis of spirometry/exercise testing with regards to symptoms

\begin{tabular}{|c|c|c|c|}
\hline & With fatigue & Without fatigue & $P$-value \\
\hline $\begin{array}{l}\text { Percent predicted (\%) } \\
\text { FEV }_{1}\end{array}$ & $90.4(89) \pm 22.2$ & $97.6(93) \pm 14.1$ & 0.37 \\
\hline $\begin{array}{l}\text { Percent predicted (\%) } \\
\text { FVC }\end{array}$ & $102(104) \pm 16.3$ & $107(104) \pm 14.4$ & 0.48 \\
\hline $\mathrm{FEV}_{1}$-to-FVC ratio & $77.0(78) \pm 16$ & $77.5(77) \pm 11$ & 0.94 \\
\hline $\begin{array}{l}\text { Percent predicted (\%) } \\
\text { FEF }_{25-75}\end{array}$ & $69.1(71.5) \pm 29.3$ & $72.2(70) \pm 31.8$ & 0.86 \\
\hline $\begin{array}{l}\text { Percent predicted }(\%) \\
\text { HR }\end{array}$ & $85.5(84.5) \pm 9.91$ & $94.8(95) \pm 26$ & 0.26 \\
\hline $\begin{array}{l}\text { Percent predicted (\%) } \\
\mathrm{VO}_{2 \max }\end{array}$ & $70.1(69) \pm 18.3$ & $90.3(90) \pm 27.6$ & $0.049^{a}$ \\
\hline $\begin{array}{l}\text { Percent with reduced } \\
\text { DBP in exercise }\end{array}$ & $75(8 / 12)$ & $64(7 / 11)$ & 1.00 \\
\hline $\begin{array}{l}\text { Reduction in DBP } \\
(\mathrm{mm} \mathrm{Hg})\end{array}$ & $21(14.5) \pm 15.8$ & $26.1(17) \pm 16.5$ & 0.31 \\
\hline \multirow{2}{*}{$\begin{array}{l}\text { Percent predicted } \\
(\%) \mathrm{V}_{\mathrm{d}} / \mathrm{V}_{\mathrm{t}}\end{array}$} & $154(141) \pm 31.1$ & $147(149) \pm 44.7$ & 0.68 \\
\hline & $\begin{array}{l}\text { With exercise } \\
\text { intolerance }\end{array}$ & $\begin{array}{l}\text { Without exercise } \\
\text { intolerance }\end{array}$ & $P$-value \\
\hline $\begin{array}{l}\text { Percent predicted (\%) } \\
\mathrm{FEV}_{1}\end{array}$ & $92.8(88.5) \pm 19.2$ & $98.5(98.5) \pm 16.5$ & 0.66 \\
\hline $\begin{array}{l}\text { Percent predicted (\%) } \\
\text { FVC }\end{array}$ & $103(104) \pm 14.8$ & $107(102) \pm 20.5$ & 0.97 \\
\hline $\mathrm{FEV}_{1}$-to-FVC ratio & $77.1(78) \pm 13.7$ & $79.0(78.5) \pm 7.26$ & 0.97 \\
\hline $\begin{array}{l}\text { Percent predicted (\%) } \\
\mathrm{FEF}_{25-75}\end{array}$ & $68.8(69) \pm 32.4$ & 90 & 0.33 \\
\hline $\begin{array}{l}\text { Percent predicted }(\%) \\
\text { HR }\end{array}$ & $83.5(86) \pm 13$ & $113(98.5) \pm 31.9$ & $0.0089^{c}$ \\
\hline $\begin{array}{l}\text { Percent predicted (\%) } \\
\mathrm{VO}_{2 \max }\end{array}$ & $75.1(71) \pm 27$ & $93.2(89) \pm 9.22$ & $0.081^{b}$ \\
\hline $\begin{array}{l}\text { Percent with Reduced } \\
\text { DBP in exercise }\end{array}$ & $70(14 / 20)$ & $50(2 / 4)$ & 0.58 \\
\hline $\begin{array}{l}\text { Reduction in DBP } \\
(\mathrm{mm} \mathrm{Hg})\end{array}$ & $22.4(19) \pm 12$ & 23 & 0.82 \\
\hline $\begin{array}{l}\text { Percent predicted (\%) } \\
\mathrm{V}_{\mathrm{d}} / \mathrm{V}_{\mathrm{t}}\end{array}$ & $154(149) \pm 36.4$ & $136(140) \pm 39.4$ & 0.43 \\
\hline
\end{tabular}

patients and $34 \%(11 / 32)$ of patients without ESRD. Type 2 diabetes was present in one woman. Based on the latest $\mathrm{Na}$ tional Cholesterol Education Program clinical practice guidelines for adult cholesterol management, ${ }^{47} 41 \%$ (14/34) of the women had fasting triglyceride levels exceeding $150 \mathrm{mg} / \mathrm{dL}$, $47 \%(15 / 32)$ had LDL cholesterol levels above goal $(<100$ $\mathrm{mg} / \mathrm{dL}$ with a prior history of coronary/cerebrovascular disease, $<130 \mathrm{mg} / \mathrm{dL}$ with two or more risk factors, $<160 \mathrm{mg} / \mathrm{dL}$ with less than two risk factors), and 15\% (5/33) had HDL cholesterol levels $<40 \mathrm{mg} / \mathrm{dL}$.

Angiotensin-converting enzyme inhibitors or angiotensin receptor blockers were taken by $26 \%(11 / 42)$ of the cohort; other medications for treatment of hypertension included di- 
Table 8

Renal data for the CSMC Fabry heterozygote cohort

\begin{tabular}{lcccc}
\hline & $\begin{array}{c}\text { No. } \\
\text { positive }\end{array}$ & $\mathrm{N}$ & Prevalence \\
\hline $\mathrm{CrCl}<90 \mathrm{~mL} / \mathrm{min} / 1.73 \mathrm{~m}^{2}$ & 21 & 36 & $58 \%$ & \\
$\mathrm{CrCl}<60 \mathrm{~mL} / \mathrm{min} / 1.73 \mathrm{~m}^{2}$ & 7 & 36 & $19 \%$ & \\
End-stage renal disease & 5 & 40 & $13 \%$ & \\
24-h urine microalbumin $>30 \mathrm{mg}$ & 8 & 10 & $80 \%$ & \\
24-h urine protein $>150 \mathrm{mg}$ & 10 & 18 & $56 \%$ & \\
& Mean & $\mathrm{SD}$ & Median & $\mathrm{N}$ \\
Blood urea nitrogen $(\mathrm{mg} / \mathrm{dL})$ & 18.8 & 15.3 & 14 & 39 \\
Serum creatinine $(\mathrm{mg} / \mathrm{dL})$ & 1.3 & 1.8 & 1.8 & 39 \\
Creatinine clearance $\left(\mathrm{mL} / \mathrm{min} / 1.73 \mathrm{~m}^{2}\right)$ & 80 & 33.3 & 83.3 & 35 \\
24-h urine microalbumin $(\mathrm{mg})$ & 621 & 1540 & 88 & 10 \\
$\quad($ normal $<30 \mathrm{mg})$ & & & & \\
24-h urine protein $(\mathrm{mg})(\mathrm{normal}<150 \mathrm{mg})$ & 1343 & 2625 & 191 & 18 \\
\hline
\end{tabular}

uretics $(29 \% ; 12 / 42)$, calcium-channel blockers (14\%; 6/42), and beta-blockers $(12 \% ; 5 / 42)$. HMG-CoA reductase inhibitors were taken by $14 \%$ (6/42) for treatment of hypercholesterolemia. Antiplatelet therapy (acetylsalicylic acid, clopidogrel, and/or dipyridamole) was used in $40 \%$ (17/42). Nonopioid pain medication was used by $29 \%$ (12/42) and included most commonly acetaminophen or ibuprofen, but also pain modulators such as gabapentin, carbamazepine, topiramate, or amitriptyline. Opioid pain medication was used by 7\% (3/42).

Antidepressant therapy, most commonly selective serotonin reuptake inhibitors, was taken by $19 \%(8 / 42)$ of the women and anxiolytic medication was taken by $10 \%(4 / 42)$. Proton pump inhibitors were taken by $19 \%$ (8/42) for treatment of gastroesophageal reflux. Albuterol and/or inhaled corticosteroids were taken by $14 \%$ (6/42) for treatment of asthma.

Eleven women were treated with ERT. The indication for initiation of ERT was pain in 45\% (5/11) of cases, cardiac involvement in $27 \%(3 / 11)$, renal disease in $27 \%(3 / 11)$, and stroke in $9 \%(1 / 11)$. One woman was treated due to a combination of severe pain and left ventricular hypertrophy. The mean duration of ERT in the 11 women treated with recombinant $\alpha$-Gal A was 25 months. ERT was better tolerated than in men: only one woman experienced hypotension, another experienced nausea and fatigue. All reactions had resolved by the tenth infusion. No anaphylactic reactions occurred. None of the three women tested developed antibodies against recombinant human $\alpha$-Gal A enzyme.

\section{Statistical comparisons between females ascertained via family history versus symptoms}

While most comparisons between heterozygotes ascertained due to a family history of Fabry disease and symptoms of Fabry disease were not significant, those ascertained from family history had significantly increased prevalence of abnormal vibration sense compared to those ascertained from symptoms
(27/31 and 5/10, respectively; $P=0.026$, Fisher's Exact Test) as well as angina pectoris ( $10 / 26$ and $0 / 10$, respectively; $P=0.035$, Fisher's Exact Test) (Table 9). The increased prevalence of abdominal cramping in the family history group approached statistical significance (14/30 and $1 / 9$, respectively; $P=0.12$, Fisher's Exact Test). Heterozygotes ascertained from family history also had worse pulmonary function tests (percent predicted $\mathrm{FEF}_{25-75}$ significant; $P=0.037$, Student's $t$-test) and better markers of renal function (blood urea nitrogen, $P=$ 0.023 ; serum creatinine, $P=0.071$; creatinine clearance, $P=$ 0.022 ; 24 -hour urine protein excretion, $P=0.046$, Wilcoxon Rank-Sum test; percent with ESRD, $P=0.010$; and percent with $\mathrm{CrCl}<60 \mathrm{~mL} /$ minute $/ \mathrm{m}^{2}, P=0.076$, Fisher's Exact Test). The serum triglyceride level in the symptoms group was also higher than the family history group in a comparison approaching significance $(P=0.12$, Student's $t$-test $)$.

\section{Symptomatology by age, mutation type, and $\alpha$-gal A enzyme activity levels}

Two symptoms were associated with significantly increased age: stroke $(57 \pm 15.3$ years in women with stroke, $44.4 \pm 16.8$ years in women without stroke, $P=0.032$ ) and angina pectoris $(54.5 \pm 13.8$ years in women with angina, $42.3 \pm 17.6$ in women without angina, $P=0.056)$. No correlations between increasing age and worsening $\mathrm{FEF}_{25-75}, \mathrm{VO}_{2 \max }$, maximum heart rate during exercise, creatinine clearance, or 24-hour protein excretion were observed. No significant differences in symptomatology were observed between women with missense versus protein-truncating mutations. Women with stroke, acroparesthesias, hypohidrosis, angina pectoris, $\mathrm{LVH}$, valvular dysfunction, gastrointestinal symptoms, or ESRD had no significant differences in plasma and leukocyte $\alpha$-gal A activity compared to women without those symptoms (unpublished data).

\section{DISCUSSION}

The heterozygotes studied in our cohort suffer from significant symptoms of Fabry disease. Only one patient (24 years old) was asymptomatic, while 40/44 women in the cohort had subjective and/or objective evidence of Fabry disease in multiple organ systems. The most common neurologic finding was decreased vibration sense in the lower extremities. Other common manifestations of peripheral neuropathy in the women were acroparesthesias and hypohidrosis. Painful abdominal cramping and diarrhea, thought to be due to $\mathrm{GL}_{3}$ storage in enteric nerve plexi and/or microvasculature, were also common. Obstructive airway disease, likely due to $\mathrm{GL}_{3}$ storage in bronchiolar smooth muscle or abnormal airway reactivity, was frequent.

Quality of life was globally reduced, especially due to fatigue (SF-36 vitality subcategory), exercise intolerance (SF-36 physical functioning subcategory), and poor self-perception of health (SF-36 general health subcategory). The Fabry heterozygote cohort PCS score was worse than the PCS score from adults with asthma and better than adults with dialysis-depen- 
Table 9

Comparison and statistical analyses for heterozygotes ascertained via family history versus symptoms

\begin{tabular}{|c|c|c|c|}
\hline General demographics & Family history & Symptoms & $P$-value \\
\hline Age (years) & $47.3(50) \pm 19.3$ & $41.4(38.5) \pm 9.2$ & 0.36 \\
\hline Age of first symptom (years) & $13.4(11) \pm 23$ & $15.8(10) \pm 15.2$ & 0.58 \\
\hline Age of diagnosis (years) & $29.7(30) \pm 22$ & $28.8(27) \pm 12.8$ & 0.90 \\
\hline Weight $(\mathrm{kg})$ & $74.1(71.5) \pm 22$ & $76.7(78.6) \pm 15$ & 0.73 \\
\hline Height $(\mathrm{cm})$ & $160.2(159.6) \pm 6.4$ & $163(163.5) \pm 6.1$ & 0.24 \\
\hline Body mass index $\left(\mathrm{kg} / \mathrm{m}^{2}\right)$ & $28.8(27.8) \pm 8.4$ & $29.0(29.5) \pm 6.3$ & 0.55 \\
\hline Body surface area $\left(\mathrm{m}^{2}\right)$ & $1.80(1.78) \pm 0.28$ & $1.86(1.88) \pm 0.19$ & 0.95 \\
\hline Plasma $\alpha$-Gal A activity (nmol/hr/mL; normal range $12 \pm 4.2)$ & $5.1(2) \pm 9.5$ & $4.2(5) \pm 3.5$ & 0.31 \\
\hline Leukocyte $\alpha$-Gal A activity $(\mathrm{nmol} / \mathrm{hr} / \mathrm{mL}$; normal range $34.6 \pm 14.6)$ & $11.2(4) \pm 17.5$ & $23.2(16) \pm 23.6$ & 0.78 \\
\hline \multicolumn{4}{|l|}{ Neurologic and psychiatric data } \\
\hline Percent with TIA & $27(7 / 26)$ & $20(2 / 10)$ & 0.99 \\
\hline Percent with stroke & $28(7 / 25)$ & $10(1 / 10)$ & 0.39 \\
\hline Percent with brain MRI c/w stroke & $37(7 / 19)$ & $20(1 / 5)$ & 0.63 \\
\hline Percent with tinnitus & $55(16 / 29)$ & $67(6 / 9)$ & 0.71 \\
\hline Percent with hearing loss & $41(12 / 29)$ & $22(2 / 9)$ & 0.44 \\
\hline Percent with hypohidrosis & $65(20 / 31)$ & $50(5 / 10)$ & 0.47 \\
\hline Percent with temperature intolerance & $52(15 / 29)$ & $40(4 / 10)$ & 0.72 \\
\hline Percent with decreased vibration sense & $87(27 / 31)$ & $50(5 / 10)$ & $0.026^{a}$ \\
\hline Percent with acroparesthesia & $63(19 / 30)$ & $67(6 / 9)$ & 0.99 \\
\hline Percent with depression/antidepressant use & $63(17 / 27)$ & $57(4 / 7)$ & 0.99 \\
\hline Percent with anxiety/anxiolytic use & $46(12 / 26)$ & $14(1 / 7)$ & 0.20 \\
\hline \multicolumn{4}{|l|}{ Cardiac data } \\
\hline Percent with angina & $39(10 / 26)$ & $0(0 / 10)$ & $0.035^{a}$ \\
\hline Percent with hypertension & $36(9 / 25)$ & $50(5 / 10)$ & 0.47 \\
\hline Percent with palpitations & $21(6 / 28)$ & $20(2 / 10)$ & 1.00 \\
\hline Percent with EKG abnormalities & $50(14 / 28)$ & $50(5 / 10)$ & 1.00 \\
\hline Percent with mitral/aortic insufficiency & $60(14 / 23)$ & $50(4 / 8)$ & 0.69 \\
\hline Heart rate $(\mathrm{bpm})$ & $67.3(66) \pm 12.6$ & $68.1(68) \pm 7.7$ & 0.85 \\
\hline PR interval (ms) & $154.2(151) \pm 25.4$ & $156(154) \pm 12.5$ & 0.85 \\
\hline IVSd (mm) & $9.8(10) \pm 1.6$ & $10.2(11) \pm 1.0$ & 0.61 \\
\hline LVPWd (mm) & $10(11) \pm 1.8$ & $10.2(11) \pm 1.8$ & 0.88 \\
\hline $\mathrm{EF} \%$ & $58.8(58) \pm 8$ & $57(55) \pm 6.4$ & 0.63 \\
\hline \multicolumn{4}{|l|}{ Pulmonary data } \\
\hline Percent predicted (\%) $\mathrm{FEV}_{1}$ & $90.5(88.5) \pm 18.2$ & $104(109) \pm 15.6$ & $0.090^{b}$ \\
\hline Percent predicted (\%) FVC & $102(104) \pm 15.6$ & $110(114) \pm 13.3$ & 0.16 \\
\hline $\mathrm{FEV}_{1}$-to-FVC ratio & $76.1(76.5) \pm 14.2$ & $81.4(79) \pm 4.4$ & 0.15 \\
\hline Percent predicted (\%) $\mathrm{FEF}_{25-75}$ & $63.0(59) \pm 27.2$ & $93.0(100) \pm 15.1$ & $0.037^{a}$ \\
\hline Percent with fatigue & $65(20 / 31)$ & $50(4 / 8)$ & 0.69 \\
\hline Percent with exercise intolerance & $80(24 / 30)$ & $100(8 / 8)$ & 0.31 \\
\hline Percent predicted (\%) HR & $92.1(88) \pm 18.9$ & $79.4(79) \pm 19.5$ & 0.15 \\
\hline Percent predicted (\%) $\mathrm{VO}_{2 \max }$ & $79.8(79) \pm 22.8$ & $75.0(86) \pm 33.3$ & $\begin{array}{c}0.68 \\
\text { (Continued) }\end{array}$ \\
\hline
\end{tabular}


Table 9

Continued

\begin{tabular}{|c|c|c|c|}
\hline General demographics & Family history & Symptoms & $P$-value \\
\hline Percent with reduced DBP in exercise & $63(12 / 19)$ & $86(6 / 7)$ & 0.37 \\
\hline Reduction in DBP (mm Hg) & $26.1(20) \pm 12$ & $26.3(17.5) \pm 17.5$ & 0.97 \\
\hline Percent predicted $(\%) \mathrm{V}_{\mathrm{d}} / \mathrm{V}_{\mathrm{t}}$ & $151(144) \pm 31.1$ & $144(134) \pm 55.4$ & 0.68 \\
\hline \multicolumn{4}{|l|}{ Gastrointestinal Data } \\
\hline Percent with abdominal pain & $47(14 / 30)$ & $11(1 / 9)$ & 0.11 \\
\hline Percent with diarrhea & $47(14 / 30)$ & $30(3 / 10)$ & 0.47 \\
\hline \multicolumn{4}{|l|}{ Renal data } \\
\hline Blood urea nitrogen (mg/dL) & $14.2(13) \pm 5.1$ & $32.0(19.5) \pm 25.5$ & $0.023^{a}$ \\
\hline Serum creatinine $(\mathrm{mg} / \mathrm{dL})$ & $0.85(0.8) \pm 0.43$ & $2.65(0.9) \pm 3.2$ & $0.071^{b}$ \\
\hline Creatinine clearance $\left(\mathrm{mL} / \mathrm{min} / 1.73 \mathrm{~m}^{2}\right)$ & $87.7(85.3) \pm 26.9$ & $59.9(74.5) \pm 41$ & $0.022^{a}$ \\
\hline Percent with $\mathrm{CrCl}<90 \mathrm{~mL} / \mathrm{min} / 1.73 \mathrm{~m}^{2}$ & $58(15 / 26)$ & $70(7 / 10)$ & 0.71 \\
\hline Percent with $\mathrm{CrCl}<60 \mathrm{~mL} / \mathrm{min} / 1.73 \mathrm{~m}^{2}$ & $12(3 / 26)$ & $40(4 / 10)$ & $0.076^{b}$ \\
\hline Percent with end-stage renal disease & $3.3(1 / 30)$ & $40(4 / 10)$ & $0.010^{a}$ \\
\hline 24 -h protein excretion $(\mathrm{mg})$ & $287(150) \pm 400$ & $5041(5381) \pm 3862$ & $0.046^{a}$ \\
\hline \multicolumn{4}{|l|}{ Other laboratory data } \\
\hline Hemoglobin (g/dL) & $13.1(13) \pm 1.1$ & $13.1(13) \pm 0.7$ & 0.96 \\
\hline Triglycerides (mg/dL) & $141.4(138) \pm 70.2$ & $191.3(143) \pm 97$ & 0.12 \\
\hline Total cholesterol (mg/dL) & $197.7(197) \pm 36.2$ & $196.9(206) \pm 29.1$ & 0.95 \\
\hline LDL cholesterol (mg/dL) & $106.5(112) \pm 34.3$ & $110.1(117) \pm 30.1$ & 0.80 \\
\hline HDL cholesterol (mg/dL) & $59.4(62) \pm 20$ & $58.4(50) \pm 18$ & 0.91 \\
\hline
\end{tabular}

${ }^{a} p<0.05 ;{ }^{b} p<0.10$.

dent end-stage renal disease, systemic lupus erythematosis, and rheumatoid arthritis; the cohort MCS score was worse than the MCS scores taken from these four chronic illness cohorts. ${ }^{39-42,48}$ Quality of life subcategory scores were comparable to scores obtained from a cohort of 202 Fabry heterozygotes. ${ }^{49}$ Data from the BPI indicates that chronic acroparesthesias, abdominal cramping, and other bodily pain interfere with mood and enjoyment of life. Pain, fatigue, exercise intolerance, and self-perception of poor health are likely to be significant contributors to the high prevalence of depression and anxiety in our cohort.

Life-threatening manifestations of Fabry disease such as cardiac ischemia, cerebrovascular accidents, hypertension, dysrhythmias, and renal insufficiency were also common. The absence of coronary artery stenosis despite electrocardiographic and serologic evidence of myocardial ischemia underscores the important observation that cardiac ischemia in Fabry disease is usually of microvascular origin. ${ }^{4,50}$ The prevalence of CVA in this cohort (22\%) was nearly ten times higher than the prevalence in the United States $(2.3 \%$ of all women older than 18 years), and the prevalence of hypertension $(43 \%)$ was more than twice that of the women in the U.S. population, perhaps due to obesity (20.2\% of women older than 20 years). ${ }^{51,52}$ This observation is in contrast to men with Fabry disease, who generally do not develop hypertension prior to onset of renal fail- ure. Equally concerning was the observed compromise in renal function, even after excluding the five women with end-stage renal disease.

The demographics of our cohort and the prevalence of most symptoms are generally similar to those reported by other groups. Some of these reports were subject to ascertainment bias due to enrollment of only symptomatic patients ${ }^{18}$ or of patients requiring ERT. ${ }^{19}$ Because $76 \%$ of our heterozygotes were ascertained due to family history of Fabry disease, the results of this study are important because they indicate that the general Fabry heterozygote population suffers from significant multisystemic disease. Furthermore, this population suffers from the same disease manifestations as hemizygous men with comparable frequency, with the exception of end-stage renal disease and left ventricular hypertrophy. $6,13,25,35,53$

The lack of differences in symptom severity between women with missense and protein-truncating mutations is consistent with our observations of intrafamilial variability. While we have not performed X-inactivation studies on any of the women, skewed X-inactivation alone cannot explain this observation. Women in this cohort with normal $\alpha$-gal A enzyme activity were just as symptomatic as women with low or absent $\alpha$-gal enzyme activity, consistent with previous studies. ${ }^{18,19}$ Variable X-inactivation within different tissues, in conjunction with differing thresholds of $\alpha$-gal A enzyme required for 
normal tissue function, may be responsible for the observed phenotypic heterogeneity. Therefore, leukocyte or plasma $\alpha$-gal A enzyme levels do not predict severity of disease or rate of progression; the presence of circulating endogenous $\alpha$-gal A enzyme cannot protect heterozygous women from development of symptoms.

Although our cohort is small, a comparison between the heterozygotes ascertained from family history and those ascertained from symptoms of Fabry disease demonstrated a significantly higher proportion of heterozygotes ascertained from family history had angina pectoris and decreased vibration sense. Abdominal cramping was also more prevalent in those diagnosed from family history, a comparison trending toward statistical significance. They also tended to have poorer performance on pulmonary function testing, indicating evidence of obstructive pulmonary disease. A possible explanation for these observations is that those diagnosed from family history tended to be older than those diagnosed from symptoms, allowing more time for $\mathrm{GL}_{3}$ storage to occur in peripheral nerves, small airways of the lungs, and microvasculature of the heart and intestines. However, no association between increasing age and worsening of these symptoms was observed, possibly due to type II error. Increasing age was correlated with CVD and angina pectoris, but this observation is more likely due to a direct effect of age and postmenopausal status, not a result of endothelial $\mathrm{GL}_{3}$ storage. Markers of renal function were poorer in the women diagnosed from symptoms because renal disease was the reason for diagnosis in $60 \%$ of those women. Triglycerides were elevated in the symptomatic group as a secondary effect of the nephrotic syndrome.

There were also significant correlations between subjective symptoms and results of noninvasive exercise testing. Women who complained of fatigue had significantly lower $\mathrm{VO}_{2 \max }$ compared to those who did not have fatigue. Those who complained of exercise intolerance had significantly lower maximum heart rates than those who did not, indicating that the inability to achieve predicted maximum exercise levels during exercise testing correlated with their subjective complaints. The high prevalence of exercise intolerance, compounded with anhidrosis and temperature intolerance, caused many of the heterozygotes to live a semisedentary lifestyle. As a possible consequence, a large proportion of our cohort was overweight or obese. The prevalence of overweight and obesity were slightly higher compared to the prevalence in the female population of the United States ( $68 \%$ and $43 \%$ vs. $62 \%$ and $33 \%$, respectively)..$^{51}$ The high prevalence of obesity, hypertension, and elevated LDL cholesterol in our cohort further augment the elevated risk of stroke and cardiac ischemia due to the endothelial $\mathrm{GL}_{3}$ storage of Fabry disease.

Based on the results of this study, we echo the recommendations of Deegan et al., 2005 that Fabry disease should no longer be termed an "X-linked recessive" disease and heterozygous Fabry women should not be called carriers, a term that erroneously connotes a lack of symptoms and dangerously delays evaluation and treatment of potentially life-threatening conditions. ${ }^{19}$ Perhaps as a result of this misconception, we have encountered resistance among the primary and specialist physicians who care for these women to evaluate and treat their Fabry disease symptoms and health insurance carriers to reimburse for their ERT. In addition, although difficult to quantify, our experience in caring for these women indicates that a number of them deny they have, or can have, significant problems with their health.

The diagnosis of Fabry disease in a proband should prompt a thorough clinical, biochemical, and molecular investigation of the rest of the proband's relatives, including women. A heterozygote should be offered ERT if they have any of the following signs or symptoms: cerebrovascular accident, TIA, or ischemic white matter changes on brain MRI; acroparesthesias resistant to conventional therapy; severe left ventricular hypertrophy, hemodynamically significant valvular dysfunction, or other clinically significant cardiac disease; or GFR $<80 \mathrm{~mL} /$ minute $/ 1.73 \mathrm{~m}^{2}$ or proteinuria resistant to pharmacotherapy. ${ }^{54}$ ERT should also be considered for microvascular cardiac ischemia and severe gastrointestinal or pulmonary/exercise intolerance symptoms resistant to medical therapy. Lifestyle modification and pharmacotherapy should be instituted to mitigate other cardiovascular risk factors such as obesity, hypertension, dyslipidemias, and platelet aggregation. Consensus recommendations for specific evaluations and pharmacotherapy have been published. ${ }^{54}$

In this study, acroparesthesia is the most common initial symptom of Fabry disease with an early age of onset, but is often not recognized and correctly referred for workup, thus delaying diagnosis and treatment. The mean time elapsed between onset of first symptom and diagnosis in our cohort was more than 15 years; earlier recognition of Fabry disease in heterozygotes will allow for earlier initiation of ERT, which can reverse or slow progression of disease.

\section{ACKNOWLEDGMENTS}

This research was supported by the American Society of Medical Genetics Foundation/Genzyme Corporation Fellowship in Clinical Biochemical Genetics (RW), the Genzyme Corporation, and CSMC General Clinical Research Center Grant Number \#M01-RR00425. The Genzyme Corporation had no formative role in data interpretation, writing or revising the manuscript, or in the decision to submit the paper for publication. We would also like to express our gratitude to Lisa Chen, MS, Stacey Wong, MS, Nilly Moore, RN, and the families who participated and made this research possible.

\section{References}

1. Brady RO, Gal AE, Bradley RM, Martensson E, et al. Enzymatic defect in Fabry's disease: Ceramide trihexosidase deficiency. N Engl J Med 1976;276:1163-1167.

2. Hughes DA, Mehta AB. Vascular complications of Fabry disease: enzyme replacement and other therapies. Acta Paediatr Suppl 2005;94:28-33.

3. Mehta A, Ginsberg L. FOS Investigators. Natural history of the cerebrovascular complications of Fabry disease. Acta Paediatr Suppl 2005;94:24-27.

4. Kampmann C, Wiethoff CM, Perrot A, Beck M, et al. The heart in Anderson Fabry disease. Z Kardiol 2002;91:786-795.

5. Shah JS, Elliott PM. Fabry disease and the heart: an overview of the natural history and the effect of enzyme replacement therapy. Acta Paediatr Suppl 2005;94:11-14.

6. Branton MH, Schiffmann R, Sabnis SG, Murray GJ, et al. Natural history of Fabry renal disease: influence of alpha-galactosidase A activity and genetic mutations on clinical course. Medicine 2002;81:122-138. 
7. Schiffmann R, Scott LJ. Pathophysiology and assessment of neuropathic pain in Fabry disease. Acta Paediatr Suppl 2002;91:48-52.

8. Dutsch M, Marthol H, Stemper B, Brys M, et al. Small fiber dysfunction predominates in Fabry neuropathy. J Clin Neurophysiol 2002;19:575-586.

9. Stemper B, Hilz MJ. Postischemic cutaneous hyperperfusion in the presence of forearm hypoperfusion suggests sympathetic vasomotor dysfunction in Fabry disease. J Neurol 2003;250:970-976.

10. Rosenberg DM, Ferrans VJ, Fulmer JD, Line BR, et al. Chronic airflow obstruction in Fabry's disease. Am J Med 1980;68:898-905.

11. Brown LK, Miller A, Bhuptani A, Sloane MF, et al. Pulmonary involvement in Fabry disease. Am J Respir Crit Care Med 1997;155:1004-1010.

12. Bierer G, Kamangar N, Balfe D, Wilcox WR, et al. Cardiopulmonary exercise testing in Fabry disease. Respiration 2005;72:504-511.

13. MacDermot KD, Holmes A, Miners AH. Anderson-Fabry disease: clinical manifestations and impact of disease in a cohort of 98 hemizygous males. J Med Genet 2001;38:750-760.

14. Desnick RJ, Ioannou YA, Eng CM. $\alpha$-Galactosidase A Deficiency: Fabry Disease. In: Scriver CR, Beaudet AL, Sly WS, Valle D, editors. The Metabolic and Molecular Bases of Inherited Disease, 8th ed. New York: McGraw Hill, 2001:3733-3774.

15. MacDermot KD, Holmes A, Miners AH. Anderson-Fabry disease: clinical manifestations and impact of disease in a cohort of 60 obligate carrier females. J Med Genet 2001;38:769-775

16. Whybra C, Kampmann C, Willers I, Davies J, et al. Anderson-Fabry disease: clinical manifestations of disease in female heterozygotes. J Inherit Metab Dis 2001;24:715724 .

17. Guffon N. Clinical presentation in female patients with Fabry disease. J Med Genet 2003;40:E38.

18. Gupta S, Ries M, Kotsopoulos S, Schiffmann R. The relationship of vascular glycolipid storage to clinical manifestations of Fabry disease: a cross-sectional study of a large cohort of clinically affected heterozygous women. Medicine 2005;84:261-268.

19. Deegan P, Baehner AF, Barba-Romero MA, Hughes D, et al. Natural history of Fabry disease in females in the Fabry Outcome Survey. J Med Genet 2006;43:347-352.

20. Ashley GA, Shabbeer J, Yasuda M, Eng CM, et al. Fabry disease: twenty novel alphagalactosidase A mutations causing the classical phenotype. J Hum Genet 2001;46: 192-196.

21. Altarescu GM, Goldfarb LG, Park KY, Kaneski C, et al. Identification of fifteen novel mutations and genotype-phenotype relationship in Fabry disease. Clin Genet 2001; 60:46-51.

22. Blaydon D, Hill J, Winchester B. Fabry disease: 20 novel GLA mutations in 35 families. Hum Mutat 2001;18:459.

23. Germain DP, Shabbeer J, Cotigny S, Desnick RJ. Fabry disease: twenty novel alphagalactosidase A mutations and genotype-phenotype correlations in classical and variant phenotypes. Mol Med 2002;8:306-312.

24. Schaefer E, Mehta A, Gal A. Genotype and phenotype in Fabry disease: analysis of the Fabry Outcome Survey. Acta Paediatr Suppl 2005;94:87-92.

25. Ortiz A, Oliveria JP, Cianciaruso B, Waldek S, et al. The Fabry registry demonstrates heterogeneity of renal progression in 833 males and females with Fabry disease. Paper presented at the European Union Lysosomal Storage Disease Symposium. Berlin, Germany, April 6-8, 2006.

26. Wilcox WR, Germain DP. For the Female Working Group of the North American and European Fabry Registry Board of Advisors. Females with X-linked Fabry disease frequently have significant organ involvement. Paper presented at the American Society of Human Genetics Meeting, New Orleans, LA, October 9-13, 2006.

27. Strottmann J, Pinderski L, Bultas J, Wanner C, et al. Cardiac involvement in Fabry disease. About numbers and notions. Paper presented at the World Congress on Heart Disease, Barcelona, Spain, September 2-6, 2006.

28. Eng CM, Banikazemi M, Gordon RE, Goldman M, et al. A phase 1/2 clinical trial of enzyme replacement in Fabry disease: pharmacokinetic, substrate clearance, and safety studies. Am J Hum Genet 2001;68:711-722.

29. Eng CM, Guffon N, Wilcox WR, Germain DP, et al. Safety and efficacy of recombinant human alpha-galactosidase A-replacement therapy in Fabry's disease. N Engl J Med 2001;345:9-16.

30. Schiffmann R, Kopp JB, Austin HA 3rd, Sabnis S, et al. Enzyme replacement therapy in Fabry disease: a randomized controlled trial. JAMA 2001;285:2743-2749.

31. Wilcox WR, Banikazemi M, Guffon N, Waldek S, et al. Long-term safety and efficacy of enzyme replacement therapy for Fabry disease. Am J Hum Genet 2004;75:65-74
32. Dehout F, Roland D, Treille de Granseigne S, Guillaume B, et al. Relief of gastrointestinal symptoms under enzyme replacement therapy in patients with Fabry disease. J Inherit Metab Dis 2004;27:499-505.

33. Bierer G, Balfe D, Wilcox WR, Mosenifar Z. Improvement in serial cardiopulmonary exercise testing post enzyme replacement therapy in Fabry disease, J Inherit Metab Dis 2006;29:572-479.

34. Banikazemi M, Bultas J, Waldek S, Wilcox WR, et al. Placebo-controlled phase 4 trial of agalsidase beta replacement therapy in Fabry disease demonstrates clinical benefit and the importance of early treatment. Submitted for publication, Ann Intern Med 2006.

35. Baehner F, Kampmann C, Whybra C, Miebach E, et al. Enzyme replacement therapy in heterozygous females with Fabry disease: results of a phase IIIB study. J Inherit Metab Dis 2003;26:617-627.

36. Cleeland CS. Pain assessment: the advantages of using pain scales in lysosomal storage diseases. Acta Paediatr Suppl 2002;91:43-47.

37. Beck M, Ricci R, Widmer U, Dehout F, et al. Fabry disease: overall effects of agalsidase alfa treatment. Eur J Clin Invest 2004;34:838-844

38. Hoffmann B, Garcia de Lorenzo A, Mehta A, Beck M, et al. Effects of enzyme replacement therapy on pain and health related quality of life in patients with Fabry disease: data from FOS (Fabry Outcome Survey). J Med Genet 2005;42:247-252.

39. Gold KF, Pastores GM, Botteman MF, Yeh JM, et al. Quality of life of patients with Fabry disease. Qual Life Res 2002;11:317-327.

40. Erickson SR, Christian RD Jr, Kirking, DM, Halman LJ. Relationship between patient and disease characteristics, and health-related quality of life in adults with asthma. Respir Med 2002;96:450-460.

41. Lowrie EG, Curtin RB, LePain N, Schatell D. Medical outcomes study short form36: a consistent and powerful predictor of morbidity and mortality in dialysis patients. Am J Kidney Dis 2003;41:1286-1292.

42. Jolly M. How does quality of life of patients with systemic lupus erythematosis compare with that of other common chronic illnesses? J Rheumatol 2005;32:1706-1708.

43. Ware JE, Kosinski M, Keller SD. SF-36 physical and mental health summary scales: A user's manual. The Health Institute, New England Medical Center, Boston, MA, 1994.

44. Cohen J. Statistical Power Analysis for Behavioral Sciences, $2^{\text {nd }}$ edition. New Jersey: Lawrence Erlbaum Associates, Inc., 1988.

45. Levey AS, Bosch JP. A more accurate method to estimate glomerular filtration rate from serum creatinine: A new predictive equation. Ann Intern Med 1999;130:461470.

46. Puliyanda DP, Wilcox WR, Bunnapradist S, Nast CC, et al. Fabry disease in a renal allograft. Am J Transplant 2003;3:1030-1032.

47. Expert Panel on Detection, Evaluation, and Treatment of High Blood Cholesterol in Adults. Executive Summary of The Third Report of The National Cholesterol Education Program (NCEP) Expert Panel on Detection, Evaluation, And Treatment of High Blood Cholesterol In Adults (Adult Treatment Panel III). JAMA 2001;285: 2486-2497.

48. Ruta DA, Hurst NP, Kind P, Hunter M, et al. Measuring health status in British patients with rheumatoid arthritis: reliability, validity and responsiveness of the short form 36-item health survey (SF-36). Br J Rheumatol 1998;37:425-436.

49. Street NJ, Yi MS, Bailey LA, Hopkin RJ. Comparison of health-related quality of life between heterozygotes women with Fabry disease, a healthy control population, and patients with other chronic disease. Genet Med 2006;8:346353.

50. Elliott PM, Kindler H, Shah JS, Sachdev B, et al. Coronary microvascular dysfunc tion in male patients with Anderson-Fabry disease and the effect of treatment with alpha galactosidase A. Heart 2006;92:357-60.

51. National Center for Health Statistics. Health, United States, 2005. Available at: http://www.cdc.gov/nchs/fastats/hyprtens.htm. Accessed on: May 30, 2006.

52. Lethbridge-Cejku M, Vickerie J. Summary health statistics for U.S. adults: National Health Interview Survey, 2003. National Center for Health Statistics. Vital Health Stat 2005;10:17.

53. Mehta A, Ricci R, Widmer U, Dehout F, et al. Fabry disease defined: baseline clinical manifestations of 366 patients in the Fabry Outcome Survey. Eur J Clin Invest 2004; 34:236-242.

54. Eng CM, Germain DP, Banikazemi M, Warnock DG, et al. Fabry disease: guidelines for the evaluation and management of multi-organ system involvement. Genet Med 2006;8:539-548. 